\title{
NO signaling functions in the biotic and abiotic stress responses
}

\author{
David Wendehenne*1, Kevin Gould ${ }^{2}$, Olivier Lamotte ${ }^{1}$, Jörg Durner ${ }^{3}$, \\ Elodie Vandelle ${ }^{1}$, David Lecourieux ${ }^{4}$, Cécile Courtois ${ }^{1}$, Laurent Barnavon ${ }^{1}$, \\ Marc Bentéjac ${ }^{1}$ and Alain Pugin ${ }^{1}$
}

\begin{abstract}
Address: ${ }^{1}$ UMR INRA 1088/CNRS 5184/Universitŭ de Bourgogne, Plante-Microbe-Environnement, 17 rue Sully, BP 86510, Dijon 21065 Cedex, France, 2 Plant Sciences Group, School of Biological Sciences, University of Auckland, Private Bag 92019, Auckland, New Zealand, ${ }^{3}$ Institute of Biochemical Plant Pathology, GSF-National Research Center for Environment and Health, D-85764 Neuherberg, Germany and ${ }^{4}$ UMR CNRS 6161, Laboratoire de Transport des Assimilats, UFR Sciences-Bâtiment Botanique, 40 avenue de Recteur Pineau, Poitiers 86022 Cedex, France

Email: David Wendehenne* - wendehen@dijon.inra.fr

* Corresponding author
\end{abstract}

from Cell Biology of Nitric Oxide and Cell Death in Plants

Yalta, Ukraine, 8-II September 2004

Published: 3I May 2005

BMC Plant Biology 2005, 5(Suppl I):S35 doi:I0.II86/I47I-2229-5-SI-S35

\section{Introduction}

Over the past two decades, it has been recognized that nitric oxide (NO) plays an important role in diverse mammalian physiological processes. NO regulates physiological processes by modulating the activity of proteins principally by nitrosylation, a process referring to the binding of NO to a transition metal centre or cysteine residues [1]. An important class of proteins that constitutes key targets of $\mathrm{NO}$ is that of the $\mathrm{Ca}^{2+}$ channels including plasma membranes as well intracellular $\mathrm{Ca}^{2+}$ channels. NO modulates these channels directly by nitrosylation, but also indirectly via the second messenger cyclic GMP (cGMP) and/or cyclic ADP ribose (cADPR). Therefore, NO emerges as a key messenger governing the overall control of $\mathrm{Ca}^{2+}$ homeostasis [2].

In the late 1990s, NO also became an increasingly popular target for investigation in plants. As in mammals, NO fulfils a broad spectrum of signaling functions in (patho)physiological processes in plants [3]. Here, we summarise studies published in recent years that provide novel insights into the signaling functions of NO produced by plant cells exposed to abiotic stresses and biotic stress (pathogen-derived elicitors). It focuses particularly on the cross-talk operating between $\mathrm{NO}$ and $\mathrm{Ca}^{2+}$.

\section{Results}

Over the past few years, we have studied the functions of NO in plant cells challenged with elicitors of defense responses. One elicitor has been used primarily: crypto- gein, a $10 \mathrm{kDa}$ elicitor produced by the oomycete Phytophthora cryptogea [4].

Using the NO sensitive fluorophore 4,5-diaminofluorescein diacetate (DAF-2DA), we reported the real-time imaging of NO production in epidermal tobacco cells treated with cryptogein [5]. After elicitation with the elicitor, the earliest burst of NO was in the chloroplasts, where NO production occurred within 3 minutes. The level of fluorescence increased with time, and after 6 minutes NO was also found along the plasma membrane, in the nucleus and most probably in peroxisomes. To investigate the signaling events that mediate NO production, and to analyse NO signaling activities in the cryptogein transduction pathway, a spectrofluorometric assay using DAF-2DA was developed to follow NO production in tobacco cultured cells. As observed in tobacco epidermal tissue, cryptogein induced a fast and transient NO production in tobacco cell suspensions [6]. This production was completely suppressed in the presence of the NO scavenger CPTIO, and was reduced by 55 to $85 \%$ by mammalian nitric oxide synthase inhibitors. By contrast, inhibitors of nitrate reductase inhibitors, a plant NO source, had no effect on cryptogein-induced NO production.

Calcium signals are thought to play an important role in the tobacco cells response to cryptogein [7]. To investigate whether NO was active in this process, the recombinant aequorin technology was used. Aequorin is a photoprotein from Aequora victoria which undergoes a conforma- 
tional change and emits luminescence when occupied by $\mathrm{Ca}^{2+}$. Using transgenic Nicotiana plumbaginifolia cell suspensions that constitutively express aequorin in the cytosol, it was shown that cryptogein triggers a biphasic increase of cytosolic free $\mathrm{Ca}^{2+}$ concentration $\left(\left[\mathrm{Ca}^{2+}\right]_{\mathrm{cyt}}\right)$ resulting from an influx of extracellular $\mathrm{Ca}^{2+}$ and $\mathrm{Ca}^{2+}$ release from internal stores [7]. When cryptogein-triggered NO production was suppressed by cPTIO or inhibitors of mammalian NOS, the intensity of the first $\left[\mathrm{Ca}^{2+}\right]_{\mathrm{cyt}}$ increase was reduced by almost $50 \%$ whereas the second $\left[\mathrm{Ca}^{2+}\right]_{\text {cyt }}$ peak was unaffected. We further provided evidence that NO appears to contribute to the elicitorinduced $\left[\mathrm{Ca}^{2+}\right]_{\text {cyt }}$ elevation by promoting the release of $\mathrm{Ca}^{2+}$ from intracellular $\mathrm{Ca}^{2+}$ stores into the cytosol [6].

Recently, the role of $\mathrm{NO}$ in controlling $\mathrm{Ca}^{2+}$ homeostasis was investigated more thoroughly. Its has been shown that NO, released by the sulphur-free NO donor DEANONOate, elicits within minutes a transient influx of extracellular $\mathrm{Ca}^{2+}$ and a synchronized increase of $\left[\mathrm{Ca}^{2+}\right]_{\mathrm{cyt}}$ in aequorin-transformed tobacco cells [6]. As predicted from a pharmacological study, the channels responsible for NO-induced $\left[\mathrm{Ca}^{2+}\right]_{\mathrm{cyt}}$ elevation include voltagedependent $\mathrm{Ca}^{2+}$ channels of the plasma membrane and intracellular $\mathrm{Ca}^{2+}$ channels sensitive to RYR and $\mathrm{IP}_{3} \mathrm{R}$ inhibitors. This observation paralleled the situation encountered in animal cells in which almost all the molecules involved in the control of $\mathrm{Ca}^{2+}$ homeostasis seem to be modulated by NO [2]. Recent evidence from our laboratory suggest that NO mediates $\left[\mathrm{Ca}^{2+}\right]_{\mathrm{cyt}}$ through multiple mechanisms including phosphorylation-dependent processes, cADPR and plasma membrane depolarisation.

Our data, along with those from other studies, highlight the crucial role of NO in protecting plants against pathogens by promoting $\mathrm{Ca}^{2+}$ mobilization but also defenseand stress-related gene expression and HR [6]. Besides pathogen attack, abiotic stressors, such as drought, salinity and extreme temperature are serious threats to agriculture. In the recent years, a significant amount of work has gone into investigating NO synthesis and functions in plants exposed to abiotic stressors. For example, it was shown both in tobacco leaf peels and tobacco suspension cells that high temperature, osmotic stress, or salinity, generate a rapid and significant surge in NO levels [8]. In contrast, light stress and mechanical injury had no apparent effect on NO production in tobacco and/or tomato. Thus, although NO synthesis can be triggered by several, disparate abiotic stressors, it cannot be considered a universal plant stress response.

\section{Conclusion}

Plants express adaptive response to allow them to confer tolerance to environmental stresses and ensure survival. NO function is signal transduction pathways during this response. Although the precise signaling functions of $\mathrm{NO}$ are poorly understood, its capacity to modulate $\mathrm{Ca}^{2+}$ homeostasis provides an extraordinary and remarkably effective way of conveying information. Little is known about the signaling consequence of the $\mathrm{NO} / \mathrm{Ca}^{2+}$ crosstalk but it is likely that modulation of the expression of stressrelated gene may occur.

\section{References}

I. Stamler JS, Lamas S, Fang FC: Nitrosylation: the prototypic redox-based signalling mechanism. Cell 200I, 106:675-683.

2. Clementi $E$ : Role of nitric oxide and its intracellular signalling pathways in the control of $\mathrm{Ca}^{2+}$ homeostasis. Biochem Pharmacol 1998, 55:713-718.

3. Wendehenne D, Durner J, Klessig DF: Nitric oxide: a new player in plant signalling and defence responses. Curr Opin Plant Biol 2004, 7:449-455.

4. Wendehenne D, Lamotte O, Frachisse JM, Barbier-Brygoo $H$, Pugin A: Nitrate efflux is an essential component of the cryptogein signaling pathway leading to defense responses and hypersensitive cell death in tobacco. Plant Cell 2002, 14:|937-1951.

5. Foissner I, Wendehenne D, Langebartels C, Durner J: In vivo imaging of an elicitor-induced nitric oxide burst in tobacco. Plant J 2000, 23:8I7-824.

6. Lamotte $O$, Gould K, Lecourieux D, Sequeira-Legrand A, LebrunGarcia A, Durner J, Pugin A, Wendehenne D: Analysis of nitric oxide signaling functions in tobacco cells challenged by the elicitor cryptogein. Plant Physiol 2004, 135:5 16-529.

7. Lecourieux D, Mazars C, Pauly N, Ranjeva R, Pugin A: Analysis and effects of cytosolic free calcium increases in response to elicitors in Nicotiana plumbaginifolia cells. Plant Cell 2002, | 4:2627-264I.

8. Gould KS, Lamotte O, Klinguer A, Pugin A, Wendehenne D: Nitric oxide production in tobacco leaf cells: a generalized stress response? Plant Cell Environ 2003, 26:185I-I862.

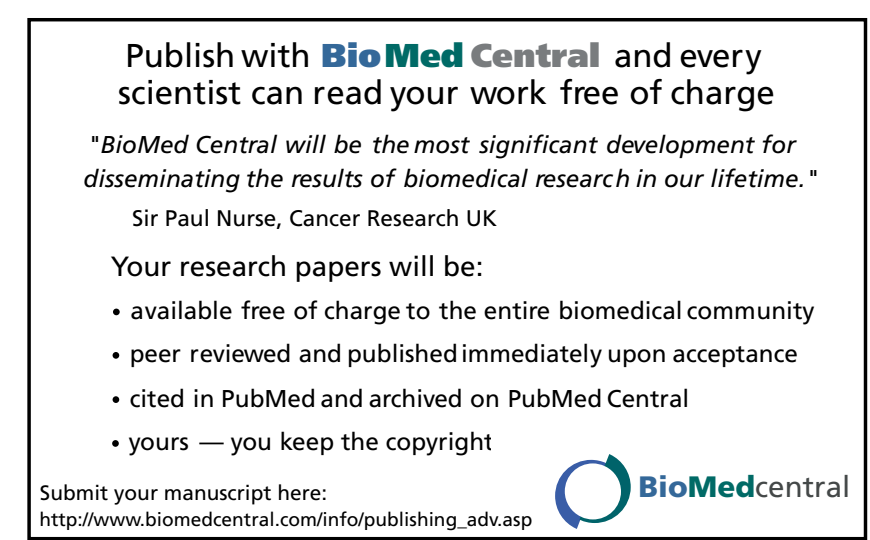

